\title{
Relationship between shoulder pain and weight of shoulder bags in young women
}

\author{
Ana Paula Vasconcellos Abdon ${ }^{1 *}$, Thais Erica Gonçalves Moraes ${ }^{1}$, Mayara Prado e Sales ${ }^{1}$, \\ Renata dos Santos Vasconcelos ${ }^{2}$, Ticiana Sampaio Braga ${ }^{1}$, Thais Sousa Pinto Ferreira ${ }^{1}$, \\ Daniela Gardano Burchales Mont'Alverne ${ }^{3}$
}

\begin{abstract}
The present study aimed to assess the relationship between shoulder pain and weight of shoulder bags in young women. Cross-sectional study conducted with 316 women aged 18-35 years from February 2013 to July 2014. A questionnaire was used to collect demographic data and information on physical activity, sleeping habits, presence of pain and its characteristics, use of bags, and percentage of bag weight-body weight ratio (\%bagweight). Pearson's chi-squared test and Mann-Whitney test were used to check for associations between the dependent variable (presence of pain) and the independent variables, with a significance level of 5\% ( $<<0.05)$. In all, $195(61.7 \%)$ women complained of shoulder pain. These women carried heavier shoulder bags $(p=0.01)$, weighing circa $4.02 \%$ of their body weight $(p=0.050)$, and the pain was proportional to a higher bag weight $(p=0.023)$ compared to the painless group. Lack of physical activity and inadequate sleep position influenced the occurrence of shoulder pain $(p=0.008$ and $p=0.017$, respectively). The weight of the shoulder bag represented a risk factor for the onset of shoulder pain and women should not carry bags weighing more than $4 \%$ of their body weight.

Keywords: shoulder pain, women, prevalence, risk factors.
\end{abstract}

\section{INTRODUCTION}

Shoulder pain is one of the main complaints in the general population resulting into functional impairment. Worldwide, women are found to present higher rates of shoulder pain, particularly associated with work activities (Abdulmonem, Hanan, Elaf, Haneen, \& Jenan, 2014; Meroni, Scelsi, Boria, \& Sansone, 2014; Hill, Gill, Menz, \& Taylor, 2010).

The shoulder is an anatomical region that undergoes different types of injuries, such as strain, inflammation, fibrosis, hypovascularization, and joint degeneration. An exposure-outcome relationship is observed between overload, work activity, psychosocial disorders, stress and unsatisfactory rest period and the presence of shoulder pain (Mendonça \& Assunção, 2005).
Among the risk factors for shoulder pain, the overload imposed on the joint and muscles by the use of some female accessories, such as bags and backpacks, is harmful to its structure (BettanySaltikov \& Cole, 2012). In addition, the characteristics of these accessories (weight, size, shape, duration of carriage) and the physical constitution of women can lead to greater damages, such as changes in body alignment, displacement of the center of gravity, excessive shoulder muscle activity, fatigue, and pain (Yoon, 2014; Dianat, Javadivala, \& Allahverdipour, 2011).

Several studies carried out with students have analyzed the weight of these accessories and demonstrated that school bags should not weigh more than $10-20 \%$ of body weight. An increase in these percentages could cause spine curvature disorders, bad posture habits, pain, learning

\footnotetext{
Manuscript received at September 29 2017 ; Accepted at June $10^{\text {th }} 2018$

${ }^{1}$ University of Fortaleza, Fortaleza, Ceará, Brazil

${ }^{2}$ Instituto Dr. José Frota, Fortaleza, Ceará, Brazil

${ }^{3}$ Federal University of Ceará, Fortaleza, Ceará, Brazil

* Corresponding author: Universidade de Fortaleza Programa de Pós-Graduação em Saúde Coletiva - PPGSC Av. Washington Soares, 1321 Bairro Edson Queiroz, CEP: 60.811-905, Brazil Email: paulaabdon@unifor.br
} 
impairment, and decreased quality of life (Yoon, 2014; Dianat et al., 2011). In addition, the frequent use of heavy backpacks has a cumulative impact on this population, leading to future health problems (Ries, Martinello, Medeiros, Cardoso, \& Santos, 2012).

In today's society, women are constantly confronted with many impositions of fashion regarding the models, sizes and styles of bags. They also must deal with aesthetics, which dictates what they should wear every day. Additionally, women's accumulation of tasks work, study, family, social events, and others coupled with the use of large and heavy shoulder bags put them at particular risk for injuries of the shoulder complex (An, Yoon, Yoo, \& Kim, 2009).

However, despite what has been said above about the repercussions of the use of shoulder bags by women, just a few studies have assessed the weight limit for this type of female accessory. Therefore, our hypothesis is that the use of overweight shoulder bags can influence the occurrence of shoulder pain.

Thus, the present study aimed to assess the relationship between shoulder pain and weight of shoulder bags in young women.

\section{METHOD}

This is a quantitative analytical cross-sectional study carried out at the University of Fortaleza (UNIFOR) from February 2013 to July 2014.

\section{Participants}

Research participants were $316 \quad(n=316)$ women aged 18-35 years enrolled in undergraduate programs. Exclusion criteria were: self-reported shoulder injuries, severe postural deviations, use of limb prosthesis/orthosis and obesity visible on inspection, and incomplete filling of the instruments used for data collection.

We used a nonprobability and intentional sample of students who were directly and informally contacted in the halls of the buildings and in the food court in different shifts. These places were chosen because they are home to students of several courses.

The study was approved by the research ethics committee of the University of Fortaleza
(Approval No. 54995). All participants provided their written consent.

\section{Procedures}

After sample selection, the authors developed a questionnaire on the basis of the literature (Mendonça \& Assunção, 2005), which was then completed by the respondents. The questionnaire addressed demographic variables (age, children, and extracurricular activity), physical activity, sleeping habits (hours and position), presence of pain and its characteristics, dominant hand, use of bags (duration of carriage, weight in kilograms - $\mathrm{kg}$, and shoulder used to carry the bag), and percentage of bag weight-body weight ratio (\%bagweight), calculated using the following formula: \%bagweight = bag weight $\mathrm{x} 100 /$ body weight.

Sleep position was self-reported and then classified into adequate (supine) and inadequate (lateral and prone) (Zenian, 2010). Pain characteristics assessed were: intensity, measured through the Visual Analog Scale (VAS), frequency and time of the day pain usually occurs. The VAS of pain intensity consists of a line with 2 descriptors representing extremes of pain intensity (e.g., no pain and extreme pain) at each end. Pain intensity is classified into mild pain (1-4), moderate (5-6) and severe pain (7-10) on a scale of 0-10 (Jensen, Chen, \& Brugger, 2003).

Body weight and bag weight were measured using a Geom ${ }^{\circledR}$ digital portable scale, with a maximum capacity of $125 \mathrm{Kg}$ and a readability of $1 \mathrm{Kg}$. Height was measured using a Sanny® portable vertical stadiometer with a $2.11 \mathrm{~m}$ capacity and an accuracy of $0.1 \mathrm{~cm}$. Height was measured in meters with the participant standing erect on barefoot looking straight ahead without any hair ornaments. Participants' Body Mass Index (BMI) were then calculated (Gordon, Chumlea, \& Roche, 1991).

Data (questionnaires and measurements) were collected by the researchers, who were previously trained in order to minimize interferences. 


\section{Statistical analysis}

The results of the numerical variables were described as mean \pm standard deviation and the results of the categorical variables were described as absolute (n) and relative (\%) values using SPSS version 20.0 (SPSS Inc., Chicago, Illinois, USA). Pearson's Chi-squared test was used to check for associations between the dependent variable (presence of pain) and the dichotomous independent variables (children, extracurricular activity, physical activity, and sleep position). Mann-Whitney test was used to investigate the relationship between the dependent variable (presence of pain) and the independent variables (bag weight, \%bagweight, sleep hours, and duration of carriage) after application of the Kolmogorov-Smirnov test to check the normality of distribution of variables. The significance level was set at $5 \%(p \leq 0.05)$.

\section{RESULTS}

The participants' mean age was $21.6 \pm 3.01$ years and the mean BMI was $22.9 \pm 3.67$. Age and BMI were similar $(\mathrm{p}=0.550$ and $\mathrm{p}=0.841$, respectively) in the pain group (age $=21.52 \pm$ 2.95 and $\mathrm{BMI}=22.95 \pm 3.62)$ and in the painless group (age $=21.73 \pm 3.12$ and $\mathrm{BMI}=23.04 \pm$ 3.76). Data on demographics, physical activity, sleep position and presence of pain were summarized in table 1 .

Of the women who complained of pain, 99 (50.7\%) reported feeling pain at night, 64 (32.9\%) said that they felt pain during the day, 20 $(10.2 \%)$ state that they felt pain during night and day, and 12 (6.2\%) did not answer. Regarding the frequency of pain, $98(50.2 \%)$ reported feeling pain every day, 94 (48.2\%) felt pain occasionally, and $3(1.6 \%)$ did not answer. With regard to pain

Table 2

Analysis of the association of shoulder pain with the weight of the bag carried and the percentage of bag weight-body weight ratio (\%bagweight) in young women. Fortaleza, Ceará, 2013-2014

\begin{tabular}{|c|c|c|c|c|}
\hline \multirow[t]{2}{*}{ Variables } & \multicolumn{2}{|c|}{$\begin{array}{c}\text { Shoulder pain } \\
\text { mean } \pm \text { D.P. (median) }\end{array}$} & \multirow[t]{2}{*}{ p-value } & \multirow[t]{2}{*}{ Effect size } \\
\hline & No & Yes & & \\
\hline Bag weight (kg) & $2.21 \pm 1.11(2.00)$ & $2.39 \pm 0.96(2.30)$ & $0.01^{* *}$ & 0.27 \\
\hline \%bagweight\# & $3.78 \pm 2.01(3.42)$ & $4.02 \pm 1.72(3.62)$ & $0.050^{*}$ & 0.13 \\
\hline Amount of sleep (hours) & $7.37 \pm 1.62(7.00)$ & $7.08 \pm 1.35(7.00)$ & 0.106 & -0.20 \\
\hline Duration of bag carriage & $2.68 \pm 2.11(2.00)$ & $2.53 \pm 2.29(2.00)$ & 0.241 & -0.29 \\
\hline
\end{tabular}

Note. D.P. $=$ standard deviation. $\#=$ percentage of bag weight-body weight ratio. ${ }^{*} p \leq 0.05$ and ${ }^{* *} p \leq 0.01$, statistically different in relation to the absence of pain (Mann-Whitney test). Effect size: d-Cohen. intensity, 55 (28.2\%) women felt mild pain, 118 (60.5\%) felt moderate pain, and 22 (11.3\%) felt severe pain.

Table 1

Distribution of demographic variables, physical activity, and sleep position in young women. Fortaleza, Ceará, 2013-2014

\begin{tabular}{lcc}
\multicolumn{1}{c}{ Variables } & $\mathrm{n}$ & $\%$ \\
\hline Age group (years) & & \\
Up to 19 & 85 & 26.9 \\
$20-24$ & 186 & 58.9 \\
$25-29$ & 35 & 11.1 \\
$30-35$ & 10 & 3.2 \\
Children & & \\
Yes & 22 & 7.0 \\
No & 294 & 93.0 \\
Extracurricular activity & & \\
Yes & 83 & 26.3 \\
No & 233 & 73.7 \\
Physical activity & & \\
Yes & 135 & 42.7 \\
No & 181 & 57.3 \\
Sleep position & & \\
Adequate & 139 & 44.0 \\
Inadequate & 177 & 56.0 \\
Shoulder pain & & \\
Yes & 195 & 61.7 \\
No & 121 & 38.3 \\
\hline
\end{tabular}

As for the dominant hand, 284 (89.9\%) participants were right-handed and 32 (10.1\%) were left-handed. With regard to the shoulder used to carry the bag, 185 (59.5\%) participants used the right shoulder, 54 (17.1\%) used the left shoulder, and 77 (24.4\%) used both shoulders.

The weight of the shoulder bags of the women who reported having joint pain was $8.14 \%$ heavier than that in the painless group $(p=0.01)$. After calculating the percentage of bag weightbody weight ratio (\%bagweight), it was found that women with pain carried bags that weighed an average of $4.02 \%$ of their body weight. Such value was significantly lower $(3.78 \%) \quad(p=0.050)$ in the painless group (Table 2). 
In addition to the previous finding, the categorization of the \%bagweight into different ranges also revealed a higher number of women with pain proportional to a higher bag weight $(p=0.023)$ (Figure 1$)$.

With regard to sleep hours and duration of carriage of the bag, there were no significant differences between the pain group and the painless groups $(p=0.106$ and $p=0.241$, respectively) (Table 2 ).
It was observed that most of the women who had children felt shoulder pain; however, this association was not significant $(p=0.172)$. Additionally, engagement in extracurricular activities did not interfere in the report of shoulder pain $(p=0.320)$. Nevertheless, physical activity and sleep position were factors that influenced the occurrence of shoulder pain in the young women analyzed $(p=0.008$ and $p=0.017$, respectively) (Table 3 ).

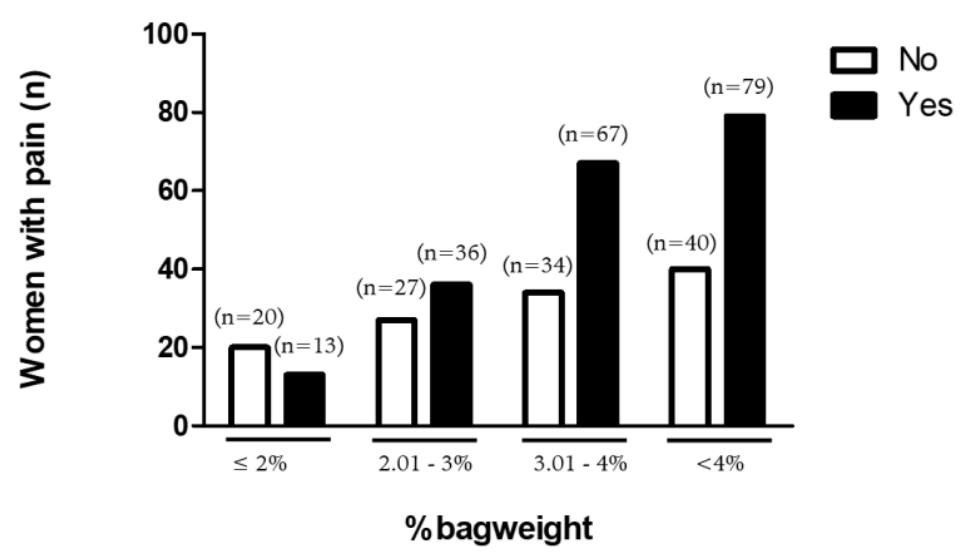

Figure 1. Distribution of women according to the occurrence of shoulder pain and the percentage of bag weightbody weight ratio (\%bagweight). Fortaleza, Ceará, 2013-2014.

Table 3

Analysis of the influence of the variables children, extracurricular activity, physical activity and sleep position on the occurrence of shoulder pain in young women. Fortaleza, Ceará, 2013-2014

\begin{tabular}{|c|c|c|c|c|c|}
\hline \multirow[b]{2}{*}{ Variables } & \multicolumn{2}{|c|}{ Shoulder pain } & \multirow[b]{2}{*}{ C.R. } & \multirow[b]{2}{*}{ p-value } & \multirow[b]{2}{*}{ Effect size } \\
\hline & $\begin{array}{c}\text { Yes } \\
\text { n (\%) }\end{array}$ & $\begin{array}{c}\text { No } \\
\text { n (\%) }\end{array}$ & & & \\
\hline \multicolumn{6}{|l|}{ Children } \\
\hline $\begin{array}{l}\text { Yes } \\
\text { No }\end{array}$ & $\begin{array}{c}17(8.7) \\
178(91.3)\end{array}$ & $\begin{array}{c}5(4.1) \\
116(95.9)\end{array}$ & $\begin{array}{c}1 \\
2.216\end{array}$ & \multirow[t]{2}{*}{0.172} & \multirow[t]{2}{*}{0.088} \\
\hline Extracurricular activ & & & & & \\
\hline $\begin{array}{l}\text { Yes } \\
\text { No }\end{array}$ & $\begin{array}{c}55(28.2) \\
140(71.8)\end{array}$ & $\begin{array}{l}28(23.1) \\
93(76.9)\end{array}$ & $\begin{array}{c}1 \\
1.305\end{array}$ & \multirow[t]{2}{*}{0.320} & 0.056 \\
\hline Physical activity & & & & & \\
\hline $\begin{array}{l}\text { Yes } \\
\text { No }\end{array}$ & $\begin{array}{c}72(36.9) \\
123(63.1)\end{array}$ & $\begin{array}{l}63(52.1) \\
58(47.9)\end{array}$ & $\begin{array}{c}1 \\
0.539\end{array}$ & \multirow[t]{2}{*}{$0.008^{* *}$} & -0.149 \\
\hline Sleep position & & & & & \multirow[b]{2}{*}{0.134} \\
\hline $\begin{array}{l}\text { Adequate } \\
\text { Inadequate }\end{array}$ & $\begin{array}{l}96(49.2) \\
99(50.8)\end{array}$ & $\begin{array}{l}43(35.5) \\
78(64.5)\end{array}$ & $\begin{array}{c}1 \\
1.103\end{array}$ & $0.017^{* *}$ & \\
\hline
\end{tabular}

Note. C.R. $=$ Chance Ratio. ${ }^{* *} p \leq 0.01$, association between variables (Pearson's Chi-squared test). Effect size: Phi coefficient.

\section{DISCUSSION}

Some conditions imposed on the shoulder complex, such as the weight of a shoulder bag, can lead to functional and anatomical changes. There are many studies on the effects of backpack use (Yoon, 2014; Hardie, Haskew, Harris, \& Hughes, 2015), particularly on schoolchildren
(Dianat et al., 2011, Ries et al., 2012). However, there is a scarcity of studies on the use of female shoulder bag and on the maximum weight recommended to minimize the harmful and chronic impact on such joint.

The relationship between shoulder pain and use of bags of various sizes and shapes has been 
shown in several studies across all continents; however, these studies have been mainly focused on children and adolescents (Hardie et al., 2015; Mwaka, Munabi, Buwembo, Kukkiriza, \& Ochieng, 2014; Matsuo, Hashimoto, Koyanagi, \& Hashizume, 2008; Zultowski \& Aruin, 2008; Chansirinukor, Wilson, Grimmer, \& Dansie, 2001). Some studies have shown groups with a large age range (7-17 years old) complaining of pain in different regions associated with the use of backpacks (Dianat et al., 2011; Myrtveit et al., 2014); in addition, women were found to be more vulnerable to the onset of backpack-related pain (Dianat et al., 2011).

In the present study, the study population consisted of young women - mostly aged 20-24 years old $(58.9 \%)$ - using a type of bag different from that used by schoolchildren, i.e., the female bags in the present study had a unilateral shoulder strap instead of bilateral shoulder straps.

Shoulder pain is a common complaint in women that may be associated with anatomical, environmental, or social factors and that have different prevalence rates. A study conducted in Middle East with female teachers aged over 20 years showed a high prevalence $(60.6 \%)$ of shoulder pain and highlighted that factors such as physical activity and satisfaction with work environment were associated with pain (Abdulmonem et al., 2014). On the other hand, research conducted in Europe with women aged 20-55 years found a lower prevalence $(25.5 \%)$ of shoulder pain (Meroni et al., 2014).

In the present study, the prevalence rate $(61.7 \%)$ of shoulder pain in young women aged 18-35 years was higher than those previously reported. Despite the different rates reported in the literature, the occurrence of shoulder pain in this population is of great concern as it is a working-age population of women of reproductive age; therefore, this type of pain may have a negative impact on their daily and labor activities.

Repeated exposure of the shoulder and neck muscles to heavy bags over a long period of time predisposes women of all ages to chronic pain in these regions (Shan et al., 2014). Unlike acute pain, chronic pain is not related to warning signs, but to a symptom that persists and tends not to disappear after the elimination of the causative factor. Persistent and long-term pain can be disturbing and may cause changes in physical activity, sleep, sex life, mood, self-esteem, and family, work and leisure relationships; additionally, it can lead to negative or suicidal thoughts (Sallum, Garcia, \& Sanches, 2012). Because of that, the assessment of chronic pain should be thorough - due to its multicausality and include information on the frequency, time of the day it usually occurs, intensity, duration, among others.

Research conducted in Asia with students aged 15-19 years highlighted the schoolbag weight as one of the risk factors identified and found that more than half of the female participants $(66.6 \%)$ experienced pain once a week and that $56.5 \%$ felt mild pain (Shan et al., 2014).

The pain characteristics among the participants of the present study were worse compared to those found in the Asian study (Shan et al., 2014). In our research, $50.2 \%$ of the women reported feeling pain every day and $60.5 \%$ felt moderate pain. These results suggest that the continuous carriage of heavy bags intensifies the injurious stimulus imposed on the shoulder complex and consequently worsens the symptomatology.

Such overload, regardless of bag types and ways of carrying them, causes injuries to the shoulders, arms, hands and back. Furthermore, unilateral load carriage causes postural changes, such as spine curvature (Bettany-Saltikov \& Cole, 2012), spine rotation (Filaire et al., 2001) and shoulder elevation (Korovessis, Koureas, \& Papazisis, 2004), in addition to excessive neck and shoulder muscle activity (Bettany-Saltikov \& Cole, 2012).

As regards the muscles directly affected by heavy bag carriage, excessive upper trapezius muscle activity has been observed in a study conducted with students (Yoon, 2014). The same study also reports lower muscle activity when walking with a backpack because of weight distribution on the shoulders. However, a preliminary study in North America with volunteers (mean age of 24 years) has 
investigated the effects of using unilateral strap shoulder bag and recommended its use on the non-dominant shoulder draped across the body in order to minimize postural deviations, risk of biomechanical problems and back pain in adulthood (Qureshi \& Shamus, 2012).

Considering bag weight, most studies agree that people using backpacks should not carry a weight greater than $10 \%$ of their body weight (Hardie et al., 2015; Yoon, 2014; Qureshi \& Shamus, 2012). However, there is a scarcity of studies on the maximum weight indicated for shoulder bags. For instance, in the study by Qureshi and Shamus (2012) on the impact of unilateral strap shoulder bag use on postural asymmetry and its repercussions, the weight used in the research was still the one recommended for backpacks, i.e., $10 \%$ of body weight.

In addition to the weight of the bag and the different ways of carrying it, other factors may also influence the occurrence or worsening of shoulder pain in young women. A study with European female students showed that physical activity reduced the risk of NSP - a protective relationship directly proportional to the frequency of physical activity (Myrtveit et al., 2014). Another study conducted with women with chronic shoulder pain has proven the effectiveness of a physical exercise protocol in the improvement of this symptomatology (Karlsson, Gerdle, Takala, Andersson, \& Larsson, 2016). In agreement with these findings, the results of the present study revealed that physically active women less reported that shoulder pain, which suggests a positive association between regular physical activity and the reduction of such symptom.

Still with regard to potentially influencing factors, a study conducted with young women reported that insufficient quality and quantity of sleep at 16 years of age may cause pain in the future (Auvinen et al., 2010). Another study has reported an increase in the prevalence of NSP in women who slept 6 hours or less a day. The same study highlights that these insomnia symptoms are more frequent in the population experiencing chronic pain (Salazar, Dueñas, Ojeda, \& Failde, 2014). In the present study, the amount of sleep, measured in hours, did not prove to be a relevant factor for the occurrence of shoulder pain.

However, when sleep position was analyzed, women with pain were found to sleep in an inadequate position, which suggests that this habit may be a risk factor for the onset of shoulder pain. In the present study, the supine position was chosen as adequate because there is greater muscle relaxation and less stress at shoulder joint and spinal curvature. In agreement with this finding, a meta-analysis of the relationship between sleep position and shoulder pain conducted by Zenian (2010) showed that the lateral position is considered potentially harmful because it entails a smaller area of contact between the body and the bed and therefore a greater pressure on this body region. In addition to this, immobility in this position may exacerbate pain due to the recurrent effect of the sleep position.

Finally, the present study showed a high prevalence of shoulder pain in a young population. In addition, the characteristics and intensity of this symptomatology have been highlighted and have pointed to a chronic pain condition. It was also important to consider some habits as potential risk factors - for instance, lack of physical activity and sleep position.

The limitations of this study were that specific shoulder pain patient-reported outcome measures, such as the American Shoulder and Elbow Surgeons (ASES) questionnaire and the Shoulder Pain and Disability Index (SPADI) were not used; instead, we only measured the presence of shoulder pain, as we believed that the selfreport of pain would be enough to relate to the bag weight. In addition, despite observing a positive relationship between active women and painless shoulder, neither the type nor the intensity of these physical activities were evaluated, which impeded to establish a possible protective muscular mechanism that may have prevented pain in the women who participated in this study

The results of the present study point to the need for educational actions with a focus on this issue in order to prevent women from experiencing pain in their bodies at an early age. Furthermore, women should carry no more than 
$4 \%$ of their body weight when using a shoulder bag. In situations where they need to carry heavier weights, they should use other types of accessories, such as bilateral strap backpacks or wheeled bags, not exceeding the weight limit indicated in the literature.

Finally, longitudinal studies are needed to clarify biomechanical and postural changes deriving from shoulder bag weight using specific questionnaires on shoulder pain, photometry and baropodometry.

\section{CONCLUSION}

There was a high frequency of everyday pain (50.2\%) and moderate-intensity (60.5\%) shoulder pain in the young women assessed in Northeastern Brazil. The weight of the shoulder bag represented a risk factor for the onset of shoulder pain and women should not carry bags weighing more than $4 \%$ of their body weight.

Acknowledgments:
The authors are thankful to the Scientific and
Technological Development Support Foundation of
Ceará (Fundação Cearense de Apoio ao
Desenvolvimento Científico e Tecnológico - FUNCAP)
for the scientific initiation scholarship provided to
Thais Sousa Pinto Ferreira.

Conflict of interests:

Nothing to declare.

Funding:

Nothing to declare.

\section{REFERENCES}

Abdulmonem, A., Hanan, A., Elaf, A., Haneen, T., \& Jenan, A. (2014). The prevalence of musculoskeletal pain \& its associated factors among female Saudi school teachers. Pakistan Journal of Medical Sciences, 30(6), 1191-1196. doi: 10.12669/pjms.306.5778

An, D. H., Yoon, J. Y., Yoo, W. G., \& Kim, K. M. (2009). Comparisons of the gait parameters of young Korean women carrying a single-strap bag. Nursing \& Health Sciences, 12(1), 87-93. doi: 10.1111/j.1442-2018.2009.00496.x

Auvinen, J. P., Tammelin, T. H., Taimela, S. P., Zitting, P. J., Järvelin, M. R., Taanila, A. M., \& Karppinen, J. I. (2010). Is insufficient quantity and quality of sleep a risk factor for neck, shoulder and low back pain? A longitudinal study among adolescents.
European Spine Journal, 19(4), 641-649. doi: 10.1007/s00586-009-1215-2

Bettany-Saltikov, J., \& Cole L. (2012). The effect of frontpacks, shoulder bags and handheld bags on 3D back shape and posture in young university students: an ISIS2 study. Studies in Health Technology and Informatics, 176, 117-121. doi: 10.3233/978-1-61499-067-3-117

Chansirinukor, W., Wilson, D., Grimmer, K., \& Dansie, B. (2001). Effects of backpacks on students: Measurement of cervical and shoulder posture. Australian Journal of Physiotherapy, 47(2), 110-116. doi: 0.1016/S0004-9514(14)60302-0

Dianat, I., Javadivala, Z., \& Allahverdipour, H. (2011). School Bag Weight and the Occurrence of Shoulder, Hand/Wrist and Low Back Symptoms among Iranian Elementary Schoolchildren. Health Promotion Perspectives, 1(1), 76-85. doi: 10.5681/hpp.2011.008

Filaire M., Vacheron, M. F., Canneuville, G., Poumarat, G., Garcier, J. M., Harouna, Y., ... Thierry, C. (2001). Influence of the mode of loadcarriage on the static posture of the pelvic girdle and the thoracic and lumbar spine in-vivo. Surgical and Radiologic Anatomy, 23(1), 27-31. doi: 10.1007/s00276-001-0027-9

Gordon, C. C., Chumlea, W. C., \& Roche, A. F. (1991). Stature, recumbent length, and weight. In T. G. Lohman, A. F. Roche, \& R. Martorell (Eds). Anthropometric standardization reference manual (pp. 3-8). Champaign, IL: Human Kinetics.

Hardie, R., Haskew, R., Harris, J., \& Hughes, G. (2015). The effects of bag style on muscle activity of the trapezius, erector spinae and latissimus dorsi during walking in female university students. Journal of Human Kinetics, 45, 39-47. doi: 10.1515/hukin-2015-0005

Hill, C.L., Gill, T.K., Shanahan, E.M., \& Taylor, A.W. (2010). Prevalence and correlates of shoulder pain and stiffness in a population-based study: the North West Adelaide Health Study. Journal of Rheumatic Diseases, 13(3), 215-222. doi: 10.1111/j.1756-185X.2010.01475.x

Jensen, M.P., Chen, C., \& Brugger, A.M. (2003). Interpretation of visual analog scale ratings and change scores: a reanalysis of two clinical trials of postoperative pain. Journal of Pain, 4(7), 407-414. doi: 10.1016/S1526-5900(03)00716-8

Karlsson, L., Gerdle, B., Takala, E., Andersson, G., \& Larsson, B. (2016). Associations between psychological factors and the effect of homebased physical exercise in women with chronic neck and shoulder pain. Sage Open Medicine, 4. doi: $10.1177 / 2050312116668933$

Korovessis, P., Koureas, G., \& Papazisis, Z. (2004). Correlation between backpack weight and way of carrying, sagittal and frontal spinal curvatures, athletic activity, and dorsal and low back pain in schoolchildren and adolescents. Journal of Spinal Disorders \& Techniques, 17(1), 33-40. doi: 10.1097/00024720-200402000-00008 
Matsuo, T., Hashimoto, M., Koyanagi, M., \& Hashizume, K. (2008). Asymmetric load-carrying in young and elderly women: Relationship with lower limb coordination. Gait \& Posture, 28(3), 517-520. doi: 10.1016/j.gaitpost.2008.02.001

Mendonça, H.P. Jr., \& Assunção, A.A. (2005). Associação entre distúrbio do ombro e trabalho: breve revisão de literatura. Revista Brasileira de Epidemiologia, 8(2), 167-176. doi: 10.1590/S1415790X2005000200009

Meroni, R., Scelsi, M., Boria, P., \& Sansone, V. (2014). Shoulder disorders in female working-age population: a cross sectional study. BMC Musculoskeletal Disorders, 15(1), 118. doi: 10.1186/1471-2474-15-118

Mwaka, E.S., Munabi, I.G., Buwembo, W., Kukkiriza, J., \& Ochieng, J. (2014). Musculoskeletal pain and school bag use: a cross-sectional study among Ugandan pupils. BMC Research Notes, 7, 222. doi: 10.1186/1756-0500-7-222

Myrtveit, S.M., Sivertsen, B., Skogen, J.C., Frostholm, L., Stormark, K.M., \& Hysing, M. (2014). Adolescent neck and shoulder pain - The association with depression, physical activity, screen-based activities, and use of health care services. Journal of Adolescent Health, 55(3), 366372. doi: 10.1016/j.jadohealth.2014.02.016

Qureshi, Y., \& Shamus, E. (2012). Unilateral shoulder bags: Can they be worn in a way to reduce postural asymmetry? Internet Journal of Allied Health Sciences and Practice, 10(4), 23-31.
Ries, L.G., Martinello, M., Medeiros, M., Cardoso, M., \& Santos, G.M. (2012). Os efeitos de diferentes pesos de mochila no alinhamento postural de crianças em idade escolar. Motricidade, 8(4), 8795. doi: $10.6063 /$ motricidade.8(4).1556

Salazar, A., Dueñas, M., Ojeda, B., \& Failde, I. (2014). Association of painful musculoskeletal conditions and migraine headache with mental and sleep disorders among adults with disabilities, Spain, 2007-2008. Preventing Chronic Disease, 11, E30. doi: 10.5888/pcd11.130144.

Sallum, A.M.C., Garcia, D.M., \& Sanches, M. (2012). Dor aguda e crônica: revisão narrativa da literatura. Acta Paulista de Enfermagem, 25 (número especial 1), 150-154.

Shan, Z., Deng, G., Li, J., Li, Y., Zhang, Y., \& Zhao, Q. (2014). How Schooling and Lifestyle Factors Effect Neck and Shoulder Pain? Spine, 39(4), E276-283. doi: 10.1097/BRS.0000000000000124

Yoon, J.G. (2014). Correlations between Muscle Activities and Strap Length and Types of School Bag during Walking. Journal of Physical Therapy Science, 26(12), 1937-1939. doi: $10.1589 /$ jpts.26.1937

Zenian, J. (2010). Sleep position and shoulder pain. Medical Hypotheseis, 74(4), 639-643. doi: 10.1016/j.mehy.2009.11.013

Zultowski, I., \& Aruin, A. (2008). Carrying loads and postural sway in standing: The effect of load placement and magnitude. Work, 30(4), 359-368.

All content of Journal Motricidade is licensed under Creative Commons, except when otherwise specified and in content retrieved from other bibliographic sources. 